\title{
A modular approach to neutral $\mathrm{P}, \mathrm{N}$-ligands: synthesis and coordination chemistry
}

\author{
Vladislav Vasilenko ${ }^{\ddagger}$, Torsten Roth ${ }^{\ddagger}$, Clemens K. Blasius, Sebastian N. Intorp, \\ Hubert Wadepohl and Lutz H. Gade*
}

\author{
Full Research Paper \\ Address: \\ Anorganisch-Chemisches Institut, Universität Heidelberg, Im \\ Neuenheimer Feld 270, 69120 Heidelberg, Germany \\ Email: \\ Lutz H. Gade* - lutz.gade@uni-heidelberg.de \\ * Corresponding author $\ddagger$ Equal contributors \\ Keywords: \\ $\mathrm{P}, \mathrm{N}$-ligands; phosphanylformamidines; phosphine imines; transition \\ metal complexes
}

\author{
Beilstein J. Org. Chem. 2016, 12, 846-853. \\ doi:10.3762/bjoc. 12.83 \\ Received: 11 February 2016 \\ Accepted: 12 April 2016 \\ Published: 29 April 2016 \\ This article is part of the Thematic Series "Organometallic chemistry". \\ Dedicated to the memory of Peter Hofmann. \\ Guest Editor: B. F. Straub
}

(C) 2016 Vasilenko et al; licensee Beilstein-Institut.

License and terms: see end of document.

\begin{abstract}
We report the modular synthesis of three different types of neutral $\kappa^{2}-\mathrm{P}, \mathrm{N}-$ ligands comprising an imine and a phosphine binding site. These ligands were reacted with rhodium, iridium and palladium metal precursors and the structures of the resulting complexes were elucidated by means of X-ray crystallography. We observed that subtle changes of the ligand backbone have a significant influence on the binding geometry und coordination properties of these bidentate $\mathrm{P}, \mathrm{N}$-donors.
\end{abstract}

\section{Introduction}

$\mathrm{P}, \mathrm{N}$-ligands have been applied in a wide variety of chemical reactions ranging from hydrogenations $[1,2]$ and allylic substitutions $[3,4]$ to Heck reactions [5] and conjugate additions to enones [6]. Their popularity arises from the inherent electronic disparity of the phosphorus and the nitrogen donor groups, rendering one binding site a soft $\pi$-acceptor featuring a pronounced trans effect and the other site a hard $\sigma$-donor [7]. In addition, the steric and electronic properties of both donor groups can in principle be varied separately, rendering modular construction approaches particularly appealing [8].

Driven by our recent efforts to provide easily accessible, modular ligand families $[9,10]$, we have explored three differ- ent possibilities to expand the portfolio of P,N-ligands (L1-L3, Figure 1). We reasoned that suitable candidates should be accessible on a multigram scale in excellent yields starting from commercially available reagents and ideally involving a maximum of two steps. In addition, the resulting ligand families

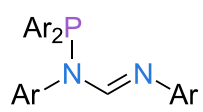

L1<smiles>CC(C)([18O])/C=N/Br</smiles>

L2<smiles>Br/N=C/c1ccccc1P=[W]</smiles>

L3
Figure 1: $\mathrm{P}, \mathrm{N}$-ligand frameworks studied in this work. 
should provide nitrogen and phosphorus donors with varying donor strength (amidine vs imine, phosphine vs heteroatombound phosphorus) and different bite angles (five- vs six-membered chelate rings).

\section{Results and Discussion Ligand synthesis}

We based the preparation of the ligand systems $\mathbf{L 1}-\mathbf{L} 3$ on a simple construction principle, i.e., only reactions of carbon- or nitrogen-nucleophiles with chlorophosphines, and condensations of amines with aldehydes were employed. For the synthesis of the $N$-phosphanylformamidine derivatives 2 and $\mathbf{3}$ we prepared a set of three aromatic formamidines $(\mathbf{1} \mathbf{a}-\mathbf{c})$ starting from triethyl orthoformate and aromatic amines. Low-temperature lithiation of $\mathbf{1}$ and addition to achiral $(\mathrm{R}=\mathrm{Ph})$ and axially chiral $\left(\mathrm{R}_{2}=\mathrm{BINOL}\right)$ chlorophosphines $\mathrm{R}_{2} \mathrm{PCl}$ gave ligands $\mathbf{2}$ and $\mathbf{3}$ in excellent yields (Scheme 1) [11]. If the correct stoichiometry is maintained throughout the reaction, the resulting mixtures do not require a purification step beyond a filtration from toluene or hexane to remove residual lithium chloride. As has been pointed out by Dyer et al. for the structurally related $N$-phosphanylamidines, there are several distinct conformers of ligands $\mathbf{2 a}-\mathbf{c}$ and $\mathbf{3 a}-\mathbf{c}$ that can exist in solution, depending on the orientation of the phosphorus lone pair, the geometry of the $\mathrm{C}=\mathrm{N}$ double bond and the orientation of the substituents of the $\mathrm{C}-\mathrm{N}$ single bond [12]. Notably, all synthesized derivatives feature a single signal in the ${ }^{31} \mathrm{P}$ NMR spectrum at room temperature, in dicating that a relatively fast interconversion of the different

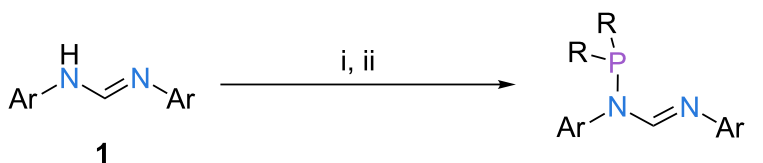

1<smiles>COc1ccc2ccccc2c1-c1c(OC)ccc2ccccc12</smiles>

Ar:<smiles>Cc1cc(C)c(I)c(C)c1</smiles><smiles>CC(C)c1cccc(C(C)C)c1I</smiles>

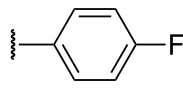

2a, $97 \%$

3a, $92 \%$

2b, $90 \%$

3b, $91 \%$ 2c, $84 \%$

3c, $87 \%$
Scheme 1: Synthesis of N-phosphanylformamidines 2 and 3. Reaction conditions: (i) $t$-BuLi, THF, $-78^{\circ} \mathrm{C}$ to rt, $1 \mathrm{~h}$; (ii) $\mathrm{R}_{2} \mathrm{PCl}$, THF, $-78^{\circ} \mathrm{C}$ to rt, overnight. conformers occurs at ambient conditions. However, with increasing steric bulk of the aromatic nitrogen substituents, a substantial line broadening is observed, indicating the rise of the isomerization barrier through steric repulsion of the neighboring groups [11].

The methodology for the synthesis of compounds $\mathbf{2}$ and $\mathbf{3}$ was also applied to the preparation of phosphine imine ligand $\mathbf{5}$. Instead of a formamidine precursor, imine $\mathbf{4}$ was employed as the nucleophile. Deprotonation of $\mathbf{4}$ at low temperature and addition of the resulting C-nucleophile to chlorodiphenylphosphine gave the desired product in good yield (Scheme 2) [13]. This modification renders the phosphorus donor site more electron rich and also results in a more robust $\mathrm{P}-\mathrm{C}$ bond compared to ligands $\mathbf{2}$ and $\mathbf{3}$.

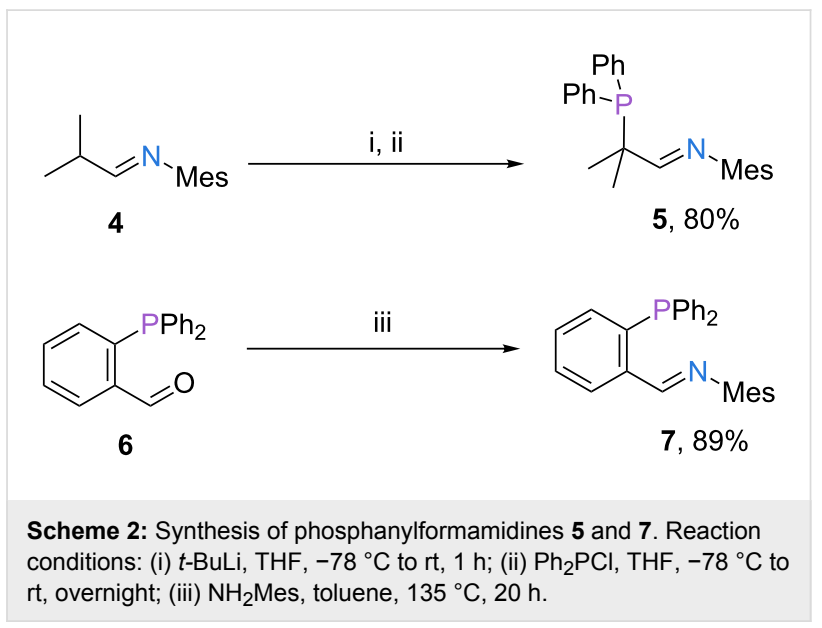

For the preparation of ligand 7 the order of bond formations of the previous protocols was reversed, that means, the carbon-nitrogen bond was formed in the second step of the synthesis. Condensation of aldehyde 6 with mesitylamine gave ligand 7 in good yield [14-16].

The connectivity of the ligands $\mathbf{2}, \mathbf{3}, \mathbf{5}$ and $\mathbf{7}$ imposes a varying level of rigidity on these bidentate donors, with distinct consequences for their coordination chemistry (vide infra).

\section{Complex synthesis}

In the next step of our study we set out to explore the coordination chemistry and structural properties of the synthesized ligands with rhodium(I/III), iridium(I/III) and palladium(II) precursors. Reaction of ligands 2 and $\mathbf{3}$ with (i) preformed $\left[\mathrm{Rh}(\operatorname{cod})_{2}\right] \mathrm{BF}_{4}$ and (ii) stoichiometric amounts of $\left[\operatorname{Ir}(\operatorname{cod}) \mathrm{Cl}_{2}\right.$ in the presence of $\mathrm{AgBF}_{4}$ gave the corresponding rhodium(I) and iridium(I) complexes $[2,3-\mathrm{M}(\operatorname{cod})] \mathrm{BF}_{4}$ in good to excellent yields (Scheme 3). In a similar fashion, analogous complexes of ligands 5 and 7 were prepared. 
<smiles>[R]PN([Al])C=N[Al]</smiles><smiles>C/N=C/C(C)(C)P(c1ccccc1)c1ccccc1</smiles>

5

2,3<smiles></smiles>

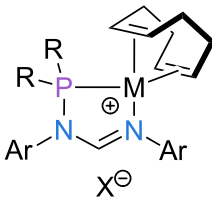

$[2,3-M(\operatorname{cod})] \mathrm{X}$<smiles>C/N=C/c1ccccc1Pc1ccccc1</smiles>

7

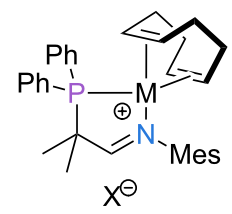

$[5-M(\operatorname{cod})] \mathrm{X}$

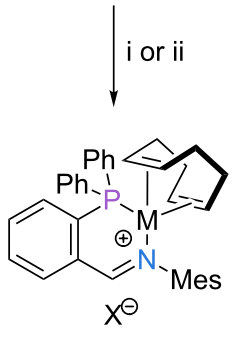

$[7-M(\operatorname{cod})] X$
Scheme 3: Synthesis of complexes [2-M(cod)]X, [3-M(cod)]X, [5-M(cod)]X and [7-M(cod)]X. M = Rh, Ir; X = $\mathrm{BF}_{4}{ }^{-}$or OTf- . Reaction conditions: (i) $\left[\mathrm{Rh}(\mathrm{cod})_{2}\right] \mathrm{BF}_{4}, \mathrm{DCM}, \mathrm{rt}, 30 \mathrm{~min}$; (ii) $\left[\operatorname{lr}(\mathrm{cod}) \mathrm{Cl}_{2}, \mathrm{AgBF}_{4}\right.$ or AgOTf, DCM, rt, 30 min. Ar = mesityl, 2,6-diisopropylphenyl, 4-fluorophenyl; $\mathrm{R}=$ phenyl or $\mathrm{BINOL}$. Yields: $[2 \mathrm{a}-\mathrm{Rh}(\mathrm{cod})] \mathrm{BF}_{4}=85 \%$, $[\mathbf{2 b}-\mathrm{Rh}(\operatorname{cod})] \mathrm{BF}_{4}=75 \%,[2 \mathrm{c}-\mathrm{Rh}(\operatorname{cod})] \mathrm{BF}_{4}=88 \%,[3 \mathrm{a}-\mathrm{Rh}(\operatorname{cod})] \mathrm{BF}_{4}=$ $74 \%$, [3b-Rh(cod)]BF $4=90 \%,[3 c-R h(\operatorname{cod})] \mathrm{BF}_{4}=81 \%$,

$[2 \mathrm{a}-\operatorname{Ir}(\operatorname{cod})] \mathrm{BF}_{4}=77 \%,[2 \mathrm{~b}-\operatorname{Ir}(\operatorname{cod})] \mathrm{BF}_{4}=80 \%,[2 \mathrm{c}-\operatorname{Ir}(\operatorname{cod})] \mathrm{BF} \mathrm{F}_{4}=88 \%$, $[3 \mathrm{a}-\operatorname{Ir}(\operatorname{cod})] \mathrm{BF}_{4}=65 \%$, [3b- $\left.\operatorname{lr}(\operatorname{cod})\right] \mathrm{BF}_{4}=81 \%,[3 \mathrm{c}-\operatorname{Ir}(\operatorname{cod})] \mathrm{BF}_{4}=82 \%$, $[5-\mathrm{Rh}(\mathrm{cod})] \mathrm{BF}_{4}=52 \%,[5-\operatorname{Ir}(\mathrm{cod})] \mathrm{OTf}=67 \%,[7-\mathrm{Rh}(\mathrm{cod})] \mathrm{BF}_{4}=92 \%$, $[7-\operatorname{Ir}(\operatorname{cod})] \mathrm{BF}_{4}=85 \%$.
It should be noted that ligands $\mathbf{2 , 5}$, and $\mathbf{7}$ feature a distinct shift of the ${ }^{31} \mathrm{P}$ NMR resonance to lower fields upon complexation of a rhodium(I) or iridium(I) center, whereas a shift to higher fields is observed for ligand 3 [11]. We were able to obtain single crystals of compounds $[\mathbf{2 a}-\mathrm{Rh}(\operatorname{cod})] \mathrm{BF}_{4},[\mathbf{2 b}-\mathrm{Rh}(\operatorname{cod})] \mathrm{BF}_{4}$, of the corresponding iridium complexes and of complexes $\left[5-\mathrm{Rh}_{(\mathrm{cod})}\right] \mathrm{BF}_{4},[5-\mathrm{Ir}(\operatorname{cod})] \mathrm{OTf}$ and $[7-\mathrm{Rh}(\operatorname{cod})] \mathrm{BF}_{4}$ suitable for X-ray analysis by layering solutions of the complexes in dichloromethane with toluene and pentane. Instructive examples of the structural properties of selected complexes are illustrated in Figure 2. An overview of characteristic bonding properties of all crystallized compounds can be found in Table 1 .

The five-membered metallacyclic derivatives of ligands $\mathbf{2}$ and $\mathbf{5}$ feature an almost planar $\kappa^{2}-\mathrm{P}, \mathrm{N}$ chelate ring with bite angles of approx. $81-82^{\circ}$. Notably, increasing the number of atoms that are part of the chelate ring leads to a slightly folded structure with only minor changes in the bite angle $\left(87^{\circ}\right)$. The nitrogenattached aryl substituent typically displays an orientation which is perpendicular to the plane of the metallacycle [17]. The P-M bond lengths in all complexes are within the expected range of 2.23-2.27 $\AA$, as are the metal-imine bonds $(2.08-2.15 \AA)$ $[18,19]$. The close structural resemblance between the rhodium

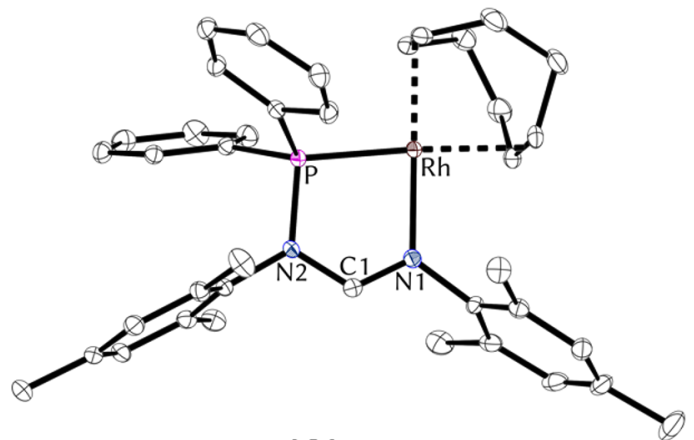

(A)

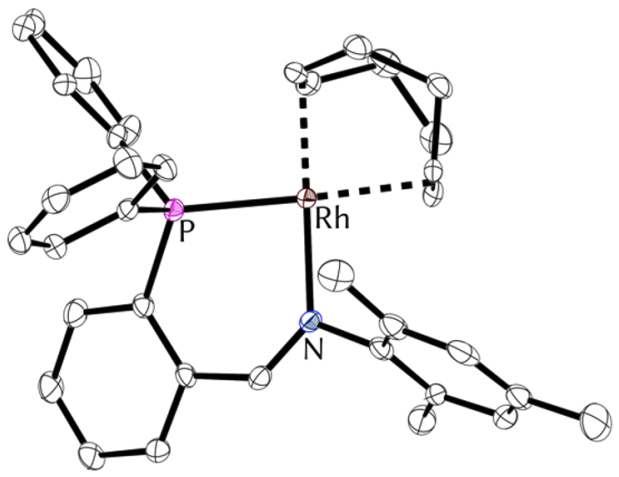

(C)

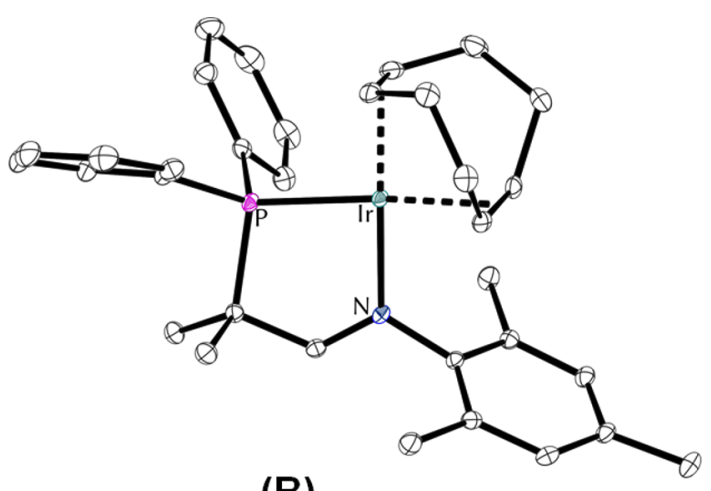

(B)

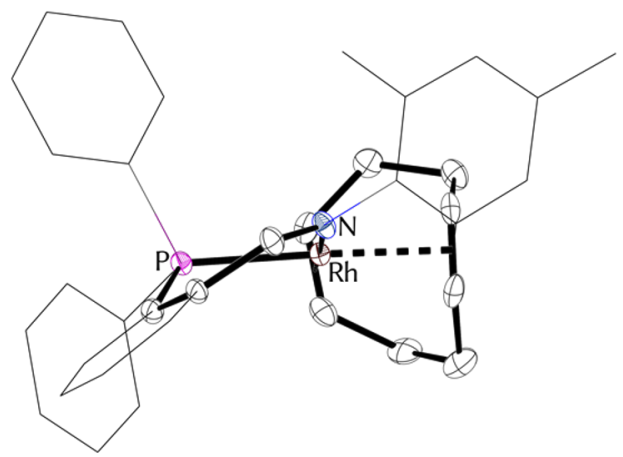

(D)

Figure 2: Molecular structures of $[2 \mathrm{a}-\mathrm{Rh}(\operatorname{cod})]^{+}(\mathrm{A}),[5-\operatorname{Ir}(\operatorname{cod})]^{+}(\mathrm{B})$, and $[7-\mathrm{Rh}(\operatorname{cod})]^{+}(\mathrm{C}, \mathrm{D})$. Anisotropic displacement ellipsoids are set at the $50 \%$ probability level. Hydrogen atoms have been omitted for clarity. For selected bond lengths and angles see Table 1. 
Table 1: Selected structural parameters of the crystallized complexes ${ }^{a}$.

\begin{tabular}{lllll} 
& $\mathrm{P}-\mathrm{M}[\AA]$ & $\mathrm{N}-\mathrm{M}[\AA]$ & $\mathrm{a}^{\mathrm{b}}\left[{ }^{\circ}\right]$ & $\beta^{\mathrm{c}}\left[^{\circ}\right]$ \\
\hline$[\mathbf{2 a}-\mathrm{Rh}(\mathrm{cod})] \mathrm{BF}_{4}$ & $2.2338(10)[2.2351(10)]$ & $2.0890(19)[2.0885(19)]$ & $122.25(19)[122.35(19)]$ & $81.69(5)[81.60(5)]$ \\
{$[\mathbf{2 b}-\mathrm{Rh}(\mathrm{cod})] \mathrm{BF}_{4}$} & $2.2487(10)[2.2452(10)]$ & $2.0981(18)[2.0907(18)]$ & $122.57(17)[122.55(17)]$ & $81.42(5)[81.75(5)]$ \\
{$[\mathbf{2 a}-\mathrm{Ir}(\mathrm{cod})] \mathrm{BF}_{4}$} & $2.2447(18)[2.2389(17)]$ & $2.083(6)[2.082(6)]$ & $122.4(7)[122.3(6)]$ & $81.49(16)[81.94(16)]$ \\
{$[\mathbf{2 b}-\mathrm{Ir}(\mathrm{cod})] \mathrm{BF}_{4}$} & $2.2522(7)[2.2473(7)]$ & $2.088(2)[2.080(2)]$ & $123.1(3)[122.9(3)]$ & $81.83(7)[81.89(7)]$ \\
{$[\mathbf{5 - R h}(\mathrm{cod})] \mathrm{BF}_{4}$} & $2.2580(10)$ & $2.1128(12)$ & $122.24(11)$ & $81.49(3)$ \\
{$[\mathbf{5}-\mathrm{Ir}(\mathrm{cod})] \mathrm{OTf}$} & $2.2698(9)$ & $2.1087(15)$ & $122.33(13)$ & $81.59(4)$ \\
{$[7-\mathrm{Rh}(\mathrm{cod})] \mathrm{BF}_{4}$} & $2.2653(12)$ & $2.131(4)$ & $129.1(4)$ & $86.65(10)$ \\
& {$[2.2587(12), 2.2654(12)]$} & {$[2.129(4), 2.155(4)]$} & {$[128.9(4), 130.0(4)]$} & {$[87.32(10), 87.66(10)]$} \\
\hline
\end{tabular}

aWhere applicable, values for crystallographically independent molecules are provided in square brackets. ${ }^{b} \alpha$ Denotes the $\mathrm{N}-\mathrm{C}-\mathrm{N}$ angle (complexes derived from ligands 2 ) or the $\mathrm{N}-\mathrm{C}-\mathrm{C}$ angle (complexes derived from ligands $\mathbf{5}$ and $\mathbf{7}$ ), respectively. ${ }^{\mathrm{C}} \beta$ Denotes the $\mathrm{N}-\mathrm{M}-\mathrm{P}$ angle.

and iridium complexes is notable and can be attributed to the similar atomic radii of these metals [20].

Moreover, the N-C-N angles of the formamidine unit closely resemble those found in related amidinium salts, thus indicating that no significant ring strain is present. The $\mathrm{M}-\mathrm{C}_{\text {cod }}$ bonds located trans to the $\mathrm{P}$ atoms are slightly longer (av $2.11 \AA$ ) than the $\mathrm{M}-\mathrm{C}_{\mathrm{cod}}$ bonds trans to the imino group (av $2.04 \AA$ ), suggesting a dominant trans influence of the phosphorus donor function compared to the imino group. The differing bond lengths within the $\mathrm{N}-\mathrm{C}-\mathrm{N}$ unit (mean 1.30 vs $1.35 \AA$ ) may indicate little or no delocalization of the positive charge via the metallacycle. Remarkably, introduction of the sterically more demanding 2,6-di(isopropyl)phenyl group as the $N$-aryl substituent induced only slight structural changes (complexes of ligand $2 \mathbf{a}$ vs $\mathbf{2 b}$ ), mostly in the orientation of the phenyl rings of the phosphorus donor and the position of the cyclooctadiene co-ligand.

To further explore the binding properties of the P,N-ligand scaffold, ligands $\mathbf{2 a}$ and $\mathbf{5}$ were reacted with the Lewis-acidic precursors $\left[\mathrm{Cp}^{*} \mathrm{RhCl}_{2}\right]_{2}$ and $\left[\mathrm{Cp} * \mathrm{IrI}_{2}\right]_{2}$ (Figure 3 ). As has been pointed out for the analogous $\mathrm{Rh}(\mathrm{I})$ and $\operatorname{Ir}(\mathrm{I})$ compounds, complexation is accompanied by a ${ }^{31} \mathrm{P}$ NMR shift to lower fields (from $49.7 \mathrm{ppm}$ to $108.9 \mathrm{ppm}$ and $80.6 \mathrm{ppm}$ for the $\mathrm{Rh}$ (III) and Ir(III) complexes of $\mathbf{2 a}$, respectively). The structures of [2a-
$\left.\mathrm{Cp}^{*} \operatorname{IrI}\right] \mathrm{BF}_{4}$, and [5-Cp*IrI] $\mathrm{BF}_{4}$ were confirmed unambiguously by single-crystal $\mathrm{X}$-ray diffraction. The solid-state structure of $[\mathbf{2} \mathbf{a}-\mathrm{Cp} * \mathrm{IrI}] \mathrm{BF}_{4}$ confirms the tetrahedral environment of the iridium center, rendering the two faces of the complex inequivalent (Figure 4, left). Similar findings were made for complex [5-Cp* $\operatorname{IrI}] \mathrm{BF}_{4}$ (Figure 4, right). This is also reflected in the NMR spectra of both complexes, featuring a distinct set of resonances for each methyl group of the mesityl substituent.

Despite the changes in the oxidation state of the metal center, only subtle deviations in the bond lengths of the chelate ligands were observed upon going from the $\operatorname{Ir}(\mathrm{I})$ to the $\operatorname{Ir}(\mathrm{III})$ complexes (in complexes of ligand 2a: avg. $2.418 \AA$ to $2.270 \AA$ for the $\mathrm{P}-\mathrm{Ir}$ bond and $2.083 \AA$ to $2.132 \AA$ for the $\mathrm{N}-\mathrm{Ir}$ bond; in complexes of ligand 5: $2.270 \AA$ to $2.305 \AA$ for the $\mathrm{P}-\mathrm{Ir}$ bond and $2.109 \AA$ to $2.136 \AA$ for the $\mathrm{N}-\mathrm{Ir}$ bond). Similarly, no major structural changes of the ligand backbone were detected for the different oxidation states.

Furthermore, due to the importance of palladium in common transition-metal-catalyzed transformations [21], we decided to explore the reactivity of the three $\mathrm{P}, \mathrm{N}$-ligand families with the widely used precursors $\left[\mathrm{Pd}(\operatorname{cod}) \mathrm{Cl}_{2}\right]$ and $[\mathrm{Pd}(\text { allyl }) \mathrm{Cl}]_{2}$ (Figure 5). Addition of ligand 2a to a solution of $\left[\mathrm{Pd}(\operatorname{cod}) \mathrm{Cl}_{2}\right]$ in DCM gave complex [2a- $\left.\mathrm{PdCl}_{2}\right]$ in good yield. In the presence of $\mathrm{AgBF}_{4}$ complex $\left[\mathbf{2 a}-\mathrm{PdCl}_{2}\right]$ was converted to the

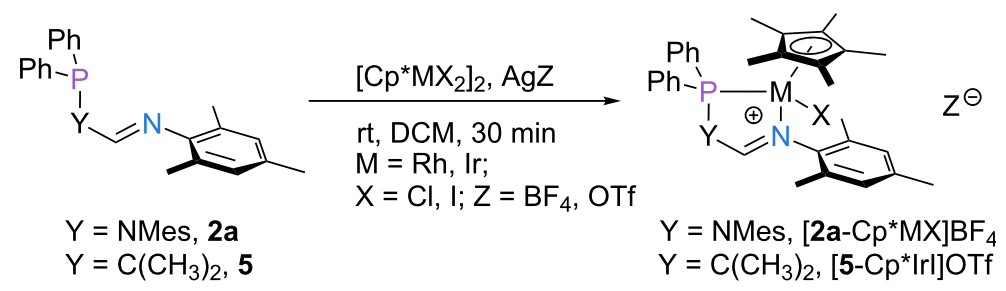

Figure 3: Coordination of ligands $\mathbf{2 a}$ and $\mathbf{5}$ to $\mathrm{Rh}(\mathrm{III})$ and $\operatorname{Ir}(\mathrm{III})$ precursors. Yields: $\left[\mathbf{2 a}-\mathrm{Cp}^{*} \mathrm{RhCl}\right] \mathrm{BF} \mathrm{F}_{4}=\mathbf{8 7} \%,\left[\mathbf{2 a}-\mathrm{Cp}^{*} \mid \mathrm{rl}\right] \mathrm{BF} 4=76 \%$, $\left[5-\mathrm{Cp}{ }^{*}|r|\right] \mathrm{OTf}=80 \%$. 

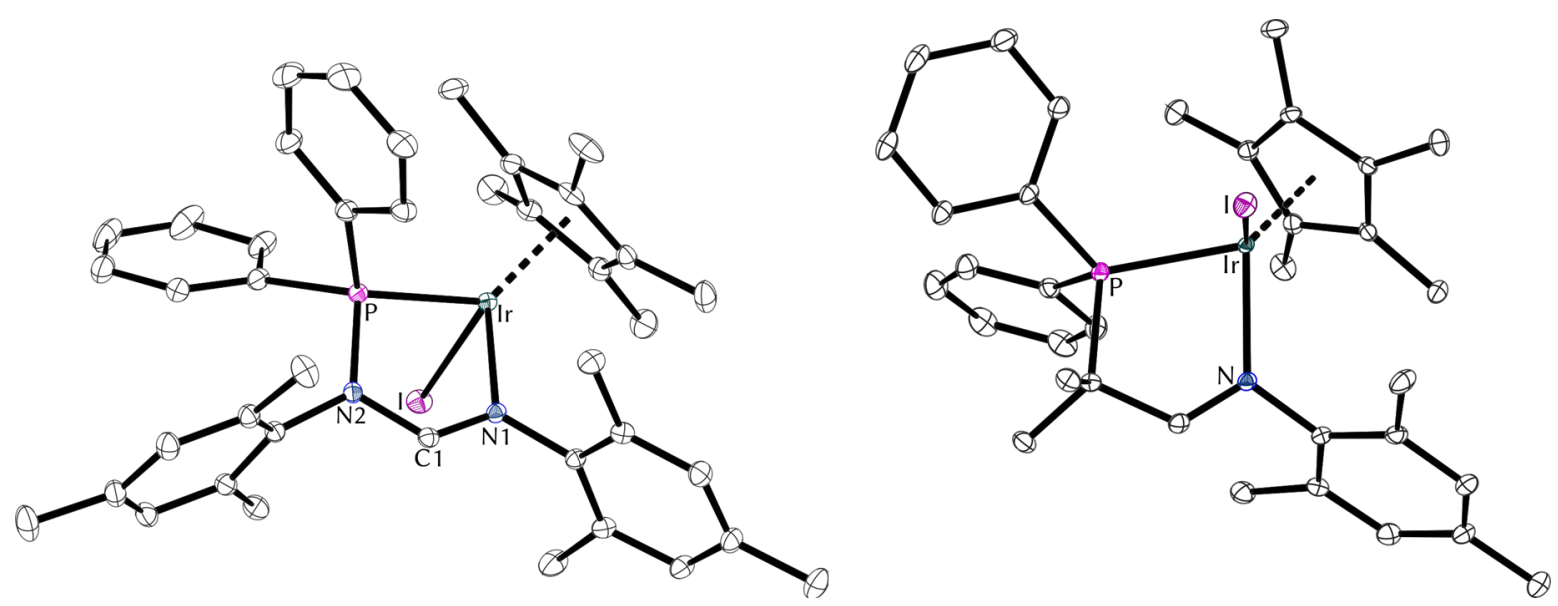

Figure 4: Molecular structures of [2a-Cp*|rl] ${ }^{+}$(left) and [5-Cp*Irl] ${ }^{+}$(right). Anisotropic displacement ellipsoids set at the $50 \%$ probability level. Hydrogen atoms have been omitted for clarity. For selected bond lengths and angles see Table 2.

Table 2: Selected structural parameters of the crystallized complexes [2a-Cp*Irl]BF 4 and [5-Cp*Irl]OTf.

\begin{tabular}{lllll} 
& $\mathrm{P}-\operatorname{Ir}[\AA]$ & $\mathrm{N}-\operatorname{Ir}[\AA]$ & $\alpha^{\mathrm{a}}\left[{ }^{\circ}\right]$ & $\beta^{\mathrm{b}}\left[{ }^{\circ}\right]$ \\
\hline$\left[2 \mathrm{a}-\mathrm{Cp}^{*} \mid \mathrm{rl}\right] \mathrm{BF}$ & & & $122.05(14)$ & $80.42(4)$ \\
{$\left[5-C p^{*} \mid \mathrm{rl}\right] \mathrm{OTf}$} & $2.2695(7)$ & $2.1322(15)$ & $124.4(2)$ & $79.75(6)$ \\
\hline
\end{tabular}

${ }^{a} \alpha$ Denotes the $N-C-N$ angle $\left(\left[2 a-C p^{*}|r|\right] B F_{4}\right)$ or the $N-C-C$ angle $\left(\left[5-C p^{*}|r|\right] O T f\right)$, respectively. ${ }^{b} \beta$ Denotes the $N-\mid r-P$ angle.

cationic palladium species $\left[\mathbf{2} \mathbf{a}-\mathrm{PdCl}_{\mathrm{B}} \mathrm{BF}_{4}\right.$, which is dimeric in the solid state [11]. Similarly, Pd(allyl) complexes of ligands 2a, 5 and 7 were obtained from mixtures of the respective ligand, $[\mathrm{Pd}(\text { allyl }) \mathrm{Cl}]_{2}$ and $\mathrm{AgBF}_{4}$ or AgOTf as the chloride scavenger in DCM (Figure 5B).

We were able to obtain single crystals of $\left[\mathbf{2 a}-\mathrm{PdCl}_{2}\right]$ and [5-Pd(2-Me-allyl)]OTf suitable for X-ray diffraction analysis (Figure 6). For an overview of metric parameters of all palladium complexes see Table 3.

The solid-state structures of [ $\left.\mathbf{2 a}-\mathrm{PdCl}_{2}\right]$ (Figure 6, left) and its cationic congener $[\mathbf{2 a}-\mathrm{PdCl}]_{2}\left(\mathrm{BF}_{4}\right)_{2}$ (Figure 5) show distinct similarities. Bond lengths and bond angles of the chelate ring agree well, underlining that halide abstraction is effectively compensated by the bridging chlorides (Table 3 ). Significant structural deviations are only observed for the $\mathrm{Pd}-\mathrm{Cl}$ bonds, where significantly longer bonds were found for the cationic species (trans-nitrogen $2.31 \AA$ vs $2.33 \AA$ and trans-phosphorus $2.33 \AA$ vs $2.42 \AA$ ). As has been observed for the corresponding rhodium and iridium complexes (vide supra), the structure of complex [5-Pd(allyl)]OTf is slightly folded, which is also accompanied by longer P-Pd and N-Pd bonds (cf. Table 2 and Table 3).

\section{Conclusion}

The work described in this paper shows that three related neutral $\kappa^{2}$-P,N-ligand families $\mathbf{L 1}-\mathbf{L 3}$ are accessible via straightforward condensation protocols. All ligand classes can be synthesized starting from cheap, commercially available reagents on a multigram scale. Notably, relatively small changes in the ligand backbone, i.e., $\mathrm{C} / \mathrm{N}$-exchange or increasing the chelate ring size, have a significant impact on the ligand geometry and its coordination properties. Thus, complexes of L1 with rhodium, iridium and palladium form planar chelate rings, structures based on $\mathbf{L} \mathbf{2}$ are slightly folded, whereas complexes of $\mathbf{L} \mathbf{3}$ exhibit a strong deviation from planarity. In summary, these results may be utilized for the design, preparation and structural elucidation of novel late transition metal complexes. Investigations into their potential as precatalysts for organic transformations are currently underway in our laboratory and will be reported in due course.

\section{Experimental}

\section{General procedure for the preparation of} ligands $\mathbf{2 ,} 3$ and 5

To a solution of the formamidine or imine $(15.0 \mathrm{mmol}$, 1.0 equiv) in $150 \mathrm{~mL}$ of THF at $-78^{\circ} \mathrm{C}$ was added dropwise a solution of tert-butyllithium in pentane $(15.0 \mathrm{mmol}, 1.0$ equiv, 


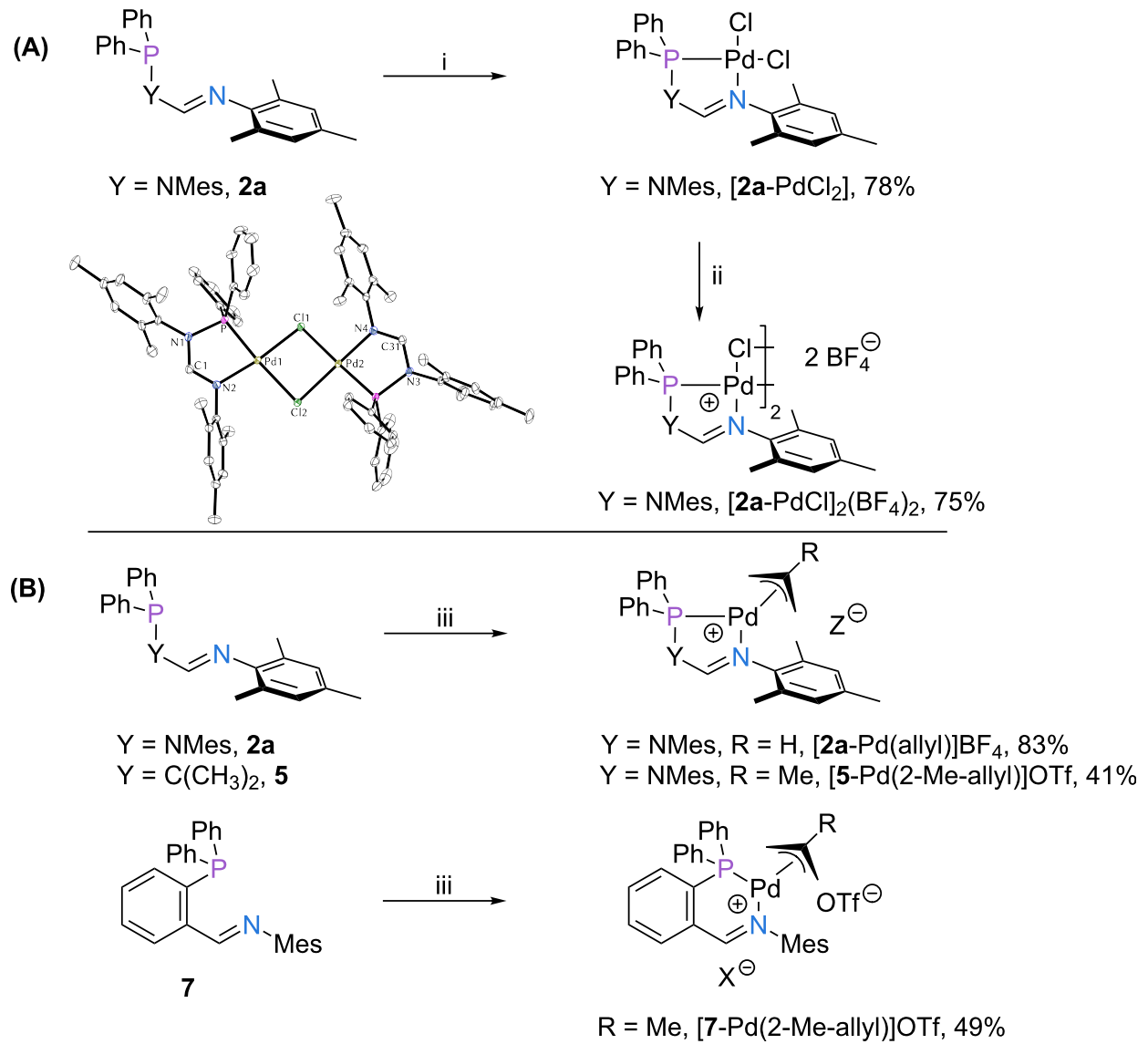

Figure 5: Formation of palladium complexes of ligands $\mathbf{2 a}, \mathbf{5}$ and $\mathbf{7}$. (A) Formation of $\left[\mathbf{2 a}-\mathrm{PdCl}_{2}\right]$ and $\left[\mathbf{2 a}-\mathrm{PdCl}_{2}\left(\mathrm{BF}_{4}\right)_{2}\right.$, and molecular structure of the dimer $[2 \mathrm{a}-\mathrm{PdCl}]_{2}{ }^{2+}$. Anisotropic displacement ellipsoids set at the $50 \%$ probability level. Hydrogen atoms have been omitted for clarity. (B) Formation of Pd(allyl) complexes of ligands 2a, 5, and 7. Reaction conditions: (i) DCM, [Pd(cod)Cl 2 , rt, 30 min; (ii) DCM, AgBF, rt, 30 min; (iii) DCM, $[\mathrm{Pd}(\text { allyl }) \mathrm{Cl}]_{2}$ or $\left[\mathrm{Pd}(2-\mathrm{Me}-\right.$ allyl $) \mathrm{Cl}_{2}, \mathrm{AgBF}_{4}$ or $\mathrm{AgOTf}, \mathrm{rt}, 30 \mathrm{~min}$.
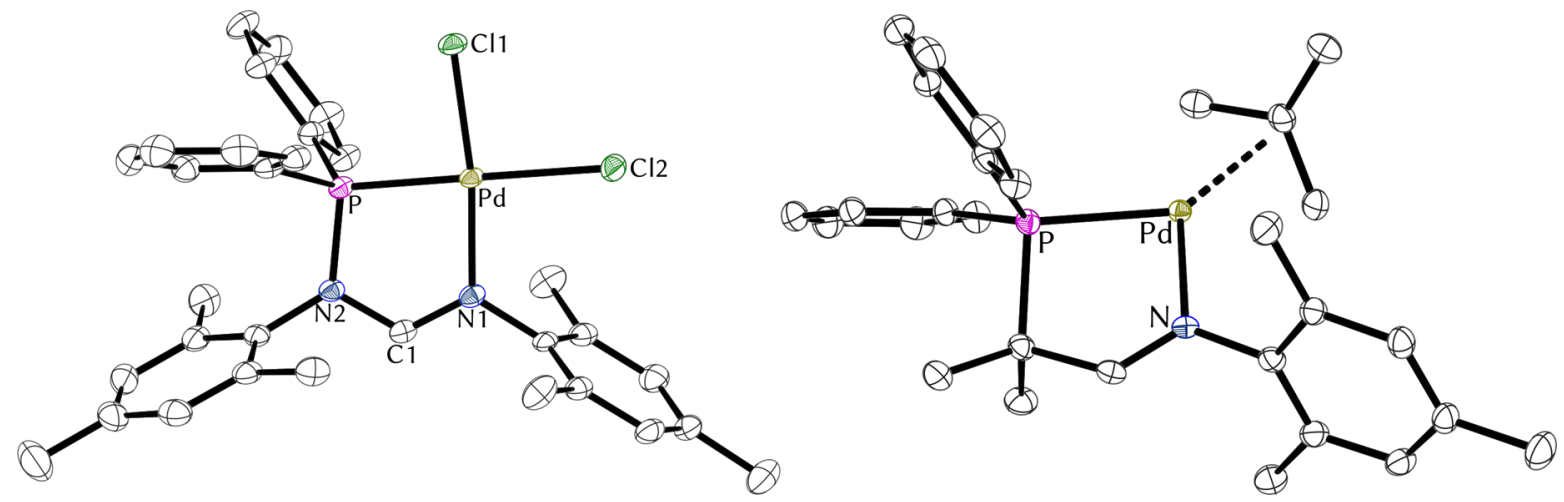

Figure 6: Molecular structures of [2a-PdCl 2$]$ (left) and [5-Pd(2-Me-allyl)] ${ }^{+}$(right). Anisotropic displacement ellipsoids set at the $50 \%$ probability level. Hydrogen atoms have been omitted for clarity.

$1.9 \mathrm{M})$. The reaction was left at this temperature for $30 \mathrm{~min}$, warmed to $\mathrm{rt}$ and stirred for $1 \mathrm{~h}$. This mixture was added to a solution of the chlorophosphine (15.0 mmol, 1.0 equiv) in
$150 \mathrm{~mL}$ of $\mathrm{THF}$ at $-78^{\circ} \mathrm{C}$, stirred for $30 \mathrm{~min}$ at this temperature and warmed to rt overnight. The solvent was removed under reduced pressure and the residue was taken up in $300 \mathrm{~mL}$ 
Table 3: Selected structural parameters of the crystallized complexes $\left[2 \mathrm{a}-\mathrm{PdCl}_{2}\right],[2 \mathrm{a}-\mathrm{PdCl}]_{2}\left(\mathrm{BF}_{4}\right)_{2}$ and $[5-\mathrm{Pd}(\mathrm{allyl})] \mathrm{OTf}$.

\begin{tabular}{lllll} 
& $\mathrm{P}-\mathrm{Pd}[\AA]$ & $\mathrm{N}-\mathrm{Pd}[\AA]$ & $\mathrm{a}^{\mathrm{a}}\left[{ }^{\circ}\right]$ & $\beta^{\mathrm{b}}\left[{ }^{\circ}\right]$ \\
\hline$\left[2 \mathrm{a}-\mathrm{PdCl}{ }_{2}\right]$ & $2.1823(7)$ & $2.043(2)$ & $121.5(2)$ & $83.59(7)$ \\
{$[2 \mathrm{a}-\mathrm{PdCl}]_{2} \mathrm{BF}_{4} \mathrm{c}$} & $2.1861(11)[2.1848(10)]$ & $2.007(2)[2.019(2)]$ & $121.4(2)[121.4(3)]$ & $83.62(7)[83.69(7)]$ \\
{$[5-\mathrm{Pd}(2-\mathrm{Me}-\mathrm{allyl})] \mathrm{OTf}$} & $2.2806(14)$ & $2.107(3)$ & $122.2(3)$ & $82.24(8)$ \\
\hline
\end{tabular}

${ }^{\mathrm{a}} \alpha$ Denotes the $\mathrm{N}-\mathrm{C}-\mathrm{N}$ angle $\left(\left[2 \mathrm{a}-\mathrm{PdCl}{ }_{2}\right],[2 \mathrm{a}-\mathrm{PdCl}]_{2} \mathrm{BF}_{4}\right)$ or the $\mathrm{N}-\mathrm{C}-\mathrm{C}$ angle $([\mathbf{5}-\mathrm{Pd}($ allyl $)] \mathrm{OTf})$, respectively. ${ }^{\mathrm{b}} \beta$ Denotes the $\mathrm{N}-\mathrm{Pd}-\mathrm{P}$ angle. ${ }^{\mathrm{c}} \mathrm{Values}$ for the second palladium center of the dimer are provided in square brackets.

of toluene. The mixture was then filtered through a plug of Celite $^{(}$and the solvent was evaporated in vacuo yielding the desired product which was used without further purification in the subsequent metalation steps. For compound numbering and the preparation of ligand 7, see Supporting Information File 1.

General procedure for the preparation of metal complexes: A solution of the ligand ( $100 \mu \mathrm{mol}, 1.0$ equiv) in $5 \mathrm{~mL}$ of $\mathrm{DCM}$ was added to the metal precursor $[\mathrm{M}]-\mathrm{X}$ (100 $\mu \mathrm{mol}, 1.0$ equiv) and the mixture was stirred for 30 minutes. At this point, the product was either isolated by layering with toluene and pentane yielding the desired neutral product or $\mathrm{AgBF}_{4}$ (alternatively AgOTf) (100 $\mu$ mol, 1.0 equiv) was added to produce the cationic complex. The suspension was then stirred in the dark for another 30 minutes, the solid residue was filtered off and the filtrate was layered with toluene and pentane, and stored at $-40{ }^{\circ} \mathrm{C}$. This procedure yielded a powder or in several cases single crystals suitable for X-ray diffraction. The solid was then washed with pentane and dried under high vacuum for several days to remove residual solvent. Alternatively, the complexes can be synthesized starting from a preformed cationic precursor $[\mathrm{M}]-\mathrm{BF}_{4}$ (or [M]-OTf). In this case, a solution of the ligand (100 $\mu$ mol, 1.0 equiv) in $5 \mathrm{~mL}$ DCM was added to the metal precursor $[\mathrm{M}]-\mathrm{BF}_{4}(100 \mu \mathrm{mol}, 1.0$ equiv). The mixture was stirred for 30 minutes, filtered, layered with toluene and pentane and stored at $-40{ }^{\circ} \mathrm{C}$. Additional purification steps were carried out as described above. For details see Supporting Information File 1.

\section{Supporting Information}

\section{Supporting Information File 1}

Experimental procedures and analytical data. [http://www.beilstein-journals.org/bjoc/content/ supplementary/1860-5397-12-83-S1.pdf]

\section{Supporting Information File 2}

Crystal structure data.

[http://www.beilstein-journals.org/bjoc/content/ supplementary/1860-5397-12-83-S2.cif]

\section{Acknowledgements}

We gratefully acknowledge the award of a Ph.D. grant to T. R. from the Landesgraduiertenförderung (LGF Funding Program of the state of Baden-Württemberg), the award of a national scholarship (Deutschlandstipendium) to V. V., C. K. B and S. N. I., and the University of Heidelberg for generous funding.

\section{References}

1. Roseblade, S. J.; Pfaltz, A. Acc. Chem. Res. 2007, 40, 1402. doi:10.1021/ar700113g

2. Lightfoot, A.; Schnider, P.; Pfaltz, A. Angew. Chem., Int. Ed. 1998, 37, 2897.

doi:10.1002/(SICI)1521-3773(19981102)37:20<2897::AID-ANIE2897>3 .0.CO;2-8

3. Helmchen, G. J. Organomet. Chem. 1999, 576, 203. doi:10.1016/S0022-328X(98)01059-6

4. Kazmaier, U., Ed. Transition Metal Catalyzed Enantioselective Allylic Substitution in Organic Synthesis; Springer: Berlin, Heidelberg, 2012; Vol. 38. doi:10.1007/978-3-642-22749-3

5. Loiseleur, O.; Hayashi, M.; Keenan, M.; Schmees, N.; Pfaltz, A. J. Organomet. Chem. 1999, 576, 16. doi:10.1016/S0022-328X(98)01049-3

6. Hu, X.; Chen, H.; Zhang, X. Angew. Chem., Int. Ed. 1999, 38, 3518. doi:10.1002/(SICI)1521-3773(19991203)38:23<3518::AID-ANIE3518>3 .0.CO;2-P

7. Pfaltz, A.; Drury III, W. J. Proc. Natl. Acad. Sci. U. S. A. 2004, 101, 5723. doi:10.1073/pnas.0307152101

8. Guiry, P. J.; Saunders, C. P. Adv. Synth. Catal. 2004, 346, 497. doi:10.1002/adsc. 200303138

9. Roth, T.; Wadepohl, H.; Wright, D. S.; Gade, L. H. Chem. - Eur. J. 2013, 19, 13823. doi:10.1002/chem.201302327

10. Roth, T.; Vasilenko, V.; Benson, C. G. M.; Wadepohl, H.; Wright, D. S.; Gade, L. H. Chem. Sci. 2015, 6, 2506. doi:10.1039/C4SC03966A

11. Carney, M. J.; Small, B. L.; Sydora, O. L. Phosphinyl Formamidine Compounds, Metal Complexes, Catalyst Systems, and their use to Oligomerize or Polymerize Olefins. WO 2015/094207 A1, June 25, 2015.

12. Baiget, L.; Batsanov, A. S.; Dyer, P. W.; Fox, M. A.; Hanton, M. J.; Howard, J. A. K.; Lane, P. K.; Solomon, S. A. Dalton Trans. 2008, 1043. doi:10.1039/B715736C

13. Daugulis, O.; Brookhart, M. Organometallics 2002, 21, 5926. doi:10.1021/om0206305

14. Xue, Z.; Linh, N. T. B.; Noh, S. K.; Lyoo, W. S. Angew. Chem. 2008, 120, 6526. doi:10.1002/ange.200801647

15. Yoshida, H.; Shirakawa, E.; Kurahashi, T.; Nakao, Y.; Hiyama, T. Organometallics 2000, 19, 5671. doi:10.1021/om000828u 
16. Shirakawa, E.; Nakao, Y.; Murota, Y.; Hiyama, T. J. Organomet. Chem. 2003, 670, 132. doi:10.1016/S0022-328X(02)02153-8

17. Nolan, S. P. N-Heterocyclic Carbenes: Effective Tools for Organometallic Synthesis; Wiley-VCH, 2014.

doi:10.1002/9783527671229

18. Roth, T.; Vasilenko, V.; Wadepohl, H.; Wright, D. S.; Gade, L. H. Inorg. Chem. 2015, 54, 7636. doi:10.1021/acs.inorgchem.5b01292

19. Hilgraf, R.; Pfaltz, A. Adv. Synth. Catal. 2005, 347, 61. doi:10.1002/adsc.200404168

20. Slater, J. C. J. Chem. Phys. 1964, 41, 3199. doi:10.1063/1.1725697

21. Tsuji, J. Palladium Reagents and Catalysts; Wiley, 2004. doi:10.1002/0470021209

\section{License and Terms}

This is an Open Access article under the terms of the Creative Commons Attribution License

(http://creativecommons.org/licenses/by/2.0), which permits unrestricted use, distribution, and reproduction in any medium, provided the original work is properly cited.

The license is subject to the Beilstein Journal of Organic Chemistry terms and conditions:

(http://www.beilstein-journals.org/bjoc)

The definitive version of this article is the electronic one which can be found at: doi:10.3762/bjoc. 12.83 